\title{
Integrating Electric Vehicles to Achieve Sustainable Energy as a Service Business Model in Smart Cities
}

\author{
Bokolo Anthony Jnr. * \\ Department of Computer Science, Norwegian University of Science and Technology, NTNU, Trondheim, Norway
}

OPEN ACCESS

Edited by:

Matthias Haase,

SINTEF, Norway

Reviewed by:

Xochitl Cruz-Núñez,

National Autonomous University of

Mexico, Mexico

Edgar Antonio Barragán,

Salesian Polytechnic

University, Ecuador

*Correspondence:

Bokolo Anthony Jnr.

anthony.j.bokolo@ntnu.no

Specialty section:

This article was submitted to

Urban Energy End-Use,

a section of the journal

Frontiers in Sustainable Cities

Received: 25 March 2021

Accepted: 10 May 2021

Published: 07 June 2021

Citation:

Anthony Jnr. B (2021) Integrating

Electric Vehicles to Achieve

Sustainable Energy as a Service

Business Model in Smart Cities.

Front. Sustain. Cities 3:685716. doi: 10.3389/frsc.2021.685716
The digitalization of the power grid to smart grid provides value added services to the prosumers and other stakeholders involved in the energy market, and possibly disrupts existing electricity services in smart cities. The use of Electric Vehicles (EVs) do not only challenge the sustainability of the smart grid but also promote and stimulate its upgrading. Undeniably, EVs can actively promote the development of the smart grid via two-way communications by deploying Vehicle-to-Grid (V2G) and Grid-to-Vehicle (G2V). EVs have environmental benefits as compared to hybrids or even internal combustion engine vehicle as they can help minimize noise levels, pollution, and greenhouse gas emissions. The integration of EVs could bring substantial changes for the society not only in providing transportation services but also shifting economies from petroleum and reducing the carbon dioxide $\left(\mathrm{CO}_{2}\right)$ emission from the transportation sector. Therefore, this study employs secondary data from the literature to explore how EVs can achieve sustainable energy as a service business model in smart cities. Findings from this study suggest that EVs are major assets for a sustainable energy future as EV batteries offers an untapped opportunity to store electricity from renewable energy sources. Implications from this study discusses the issues and recommendations for EVs integration in smart cities.

Keywords: energy informatics, sustainable energy, smart grid, business model, smart cities, Electric vehicles integration

\section{INTRODUCTION}

A smart city is a city where residents can securely gather, manage, and disseminate data that relates to all areas of their daily lives in a sustainable and ubiquitous manner (Heo et al., 2014; Anthony Jnr, 2020a). In smart cities services provided to citizens are facilitated by Information and Communication Technologies (ICT) in a resourceful manner (Zuccalà and Verga, 2017; Jnr et al., 2020a). Smart cities comprise of different sectors such as smart building, mobility, energy systems, water and air quality, climate change, etc. (Zuccalà and Verga, 2017). However, this study is aligned to Electric Vehicles (EVs) in the context of sustainable energy. Sustainable energy systems can lessen harmful emissions and increase resources usage more efficiently. Integrating EVs in smart cities may create such benefits by providing energy storage and creating new revenue streams from EVs batteries (Bedogni et al., 2013; Bohnsack et al., 2014). Presently, the adoption of EVs is increasing with global sales amounting to about $5 \%$ by 2020 . Likewise, the European Union (EU) is committed to minimize Europe's greenhouse gas emissions to about $80-95 \%$ in 2050. 
Therefore, the production and use of energy are changing as such electrical and energy systems are important infrastructures utilized in smart cities. The integration of EVs is expected to pave the way to green mobility with zero carbon emissions (Karpenko et al., 2018). Simultaneously, the use of EV are getting significant attention across the world. The emergence of EV introduces new opportunities and threats to existing energy system. Accordingly, findings from the literature reported that by the end of $2016 \sim 1.3$ million EVs were globally in used (Eider et al., 2017). EVs may range from hybrid electric cars, plug-in electric cars, and hydrogen vehicles, and may utilize one or more traction engines or electric engines for propulsion (Hinz et al., 2015). EV comprises of e-buses, e-bikes, e-cars, e-scooters, and e-railway (Kirpes et al., 2019), that contributes to reduce pollution in cities thereby achieving deep decarbonization in the transportation sector (Sanseverino and Sanseverino, 2018). Evidently, the integration of $\mathrm{EV}$ in smart cities can lead to synergies with smart demand-side systems, distributed generation, and renewable energies in improving the usage of energy assets in energy grid. This is because EV can be scheduled to recharge when energy demand is low thus generating cost savings for EV users (Weiller and Neely, 2014). Besides, EVs can serve as energy storage and supply providers if they are used in bulk by an intermediary, generally denoted to as aggregator.

Clearly the profitability of integrating EVs within the energy grid or domestic-based energy services depends on the magnitude and volatility of energy prices in the retail and wholesale energy markets (Weiller and Neely, 2014). Additionally, EVs can be suitable energy sources in the event of blackouts. In areas prone to power disruptions, such as in many emerging economies. An EV battery of about $24 \mathrm{kWh}$ (100-mile range) can provide 2 days of power supply for an individual household (Weiller and Neely, 2014). For example, EVs can offers up to $16 \mathrm{kWh}$ electricity capacity for domestic use (Weiller and Neely, 2014). Accordingly, to utilize clean energy sources EVs can be charged domestically via home generation sources such as solar panels and can further be utilized to arbitrage energy prices through smart charging and discharging, to enter decreased-price contracts with energy suppliers, and to deliver back-up electricity services in the cases of power disruptions (Weiller and Neely, 2014).

While, EVs have the precise attribute to decrease environmental degradation, cities are faced with the challenge of how to deploy business models that comprises of components required to transforms EVs as a source of economic value (Bohnsack et al., 2014). Also, prior studies related to EV usage in smart cities mainly examines the technical solutions without fully exploring the business perspective as regards to the viability or feasibility of large-scale integration of EVs in smart cities (Weiller and Neely, 2014). Grounded in the literature, this study addresses this gap in theory and practice by identifying the EV components and actors involves in achieving a sustainable energy as a service business model in smart cities. The remainder of this study is structured as follows. Section 2 is literature review, and then section 3 is the methodology. Findings is presented in section 4 . Section 5 is the discussions and implications, and section 6 is the conclusion.

\section{LITERATURE REVIEW}

Over the past years, a research trend toward the adoption of EVs has been observed in smart cities as EVs enable the decrease of urban carbon dioxide $\left(\mathrm{CO}_{2}\right)$ reduction schemes. Accordingly, few studies have been carried out in order to improve the mainstream integration of EVs by citizens in a flexible and efficient manner. Among these studies Anthony Jnr (2020b) employed enterprise architecture approach to facilitate digital transformation of EVs for electro mobility toward sustainable mobility. The author aimed to achieve data integration of electric mobility solutions from diverse stakeholders and systems involved in urban mobility services. Another study by da Silva and Santiago (2019) investigated the optimal electricity trading policy for solar powered microgrids using a modeling approach for plug-in hybrid EVs. The study highlighted that battery management is important to promote the extensive integration of microgrid connected EVs.

Additionally, Karpenko et al. (2018) explored how data exchange and interoperability cab be attained in an Internet of Things (IoT) ecosystem for EV charging and smart parking. Their research focused to resolve problem of noninteroperability that hinders seamless communication among different applications used with EVs and charging stations which uses different interoperability standards. Li et al. (2017) investigated how big data analytics can be employed to improve EV integration for green smart cities. Thus, data analytics technique was utilized for handling big data of EVs and smart grid in providing data analytics solutions and needs for EV integration to smart cities. Shuai et al. (2016) conducted a survey on EV charging in the smart city grounded on an economy driven approach. The authors provided an overview of economic approaches by considering the bidirectional energy flows and unidirectional energy flows in the energy grid via EV charging.

Furthermore, Hinz et al. (2015) aimed to improve the adoption of EV by providing complementary mobility services grounded on a two-step approach. The authors attempted to address the substantial gap regarding the use of EVs as a strategy to lessen oil consumption and reduce climate problem added by mobility services. Rodríguez et al. (2015) researched on EV integration within smart grids via interoperability solutions. The authors evaluated interoperability for all level of physical systems including stakeholder connections in providing services in relation to existing regulatory schemes and business models. Weiller and Neely (2014) examined the usage of EVs for providing energy services based on an industry perspective. A conceptual framework was proposed that identifies several services EVs can provide. Also, the factors such as social barriers, technology maturity, and corporate strategies that impacts the adoption of EVs are captured by the researchers.

Based on the reviewed studies that explored EV integration in smart grid or/and smart city. None of the studies explored how to achieve sustainable energy as a service business model in 
smart cities by considering the actors and components as well as the barriers that impends integration of EV in smart cities and recommendations to improve EV integration within smart cities.

\section{METHODOLOGY}

This study adopts a review of secondary sources to explore how EVs can achieve sustainable energy as a service business model in smart cities.

\section{Inclusion and Exclusion Criteria}

In the inclusion criteria first, the title and abstract of the retrieved sources were examined. Next, only papers that were related to EV integration in smart city or/and smart grid were included. In addition, for exclusion criteria all articles written in languages other than English language were excluded. Finally, empirical evidence was synthesized and extracted from the included articles. The selected articles were studied in detail.

\section{Search Strategies, Data Sources, and Quality Assessment}

To search for related papers an online search from digital libraries (Google Scholar, ScienceDirect, ProQuest, Springer, Wiley, IEEE Xplore, ACM, Emerald, Taylor and Francis, ISI Web of Science, Sage, Inderscience, and Scopus), were employed. These online libraries were employed because they are considered appropriate search engines for review in smart cities and sustainable energy research. To ensure that a comprehensive search was employed search terms or keywords were formulated. The search strings were framed with Boolean operators (AND, OR) to improve searching of relevant studies and to increase the quality of the search process. The main search terms comprise of electric vehicles OR Energy as a Service OR Electric vehicles integration AND business model AND smart grid AND smart cities. Thus, several articles were retrieved from digital libraries and some articles were assessed based on an inclusion and exclusion criteria in relation to the aim of the study (explore how to integrate EVs can achieve sustainable energy as a service business model in smart cities).

Figure 1 shows the Preferred Reporting Items for Systematic Reviews and Meta-Analysis (PRISMA) flowchart which was used for screening of articles as previously utilized by Anthony Jnr (2020d), Anthony Jnr and Abbas Petersen (2020). The final search resulted to 114 articles using the keywords above. No articles were established as duplicates resulting to 114 articles. The articles were checked against the inclusion and exclusion criteria and 55 sources were removed since they were not related to integrating EVs to achieve sustainable energy as a service business model in smart cities resulting to 59 articles. The remaining articles was checked for quality assessment. A check was carried out to verify if the articles were indexed in Scopus or/and ISI Web of Science databases. The findings suggest that more than half of the selected studies meet the inclusion and quality assessment criteria.

\section{Data Analysis}

Descriptive analysis was employed similar to prior study (Lin et al., 2013), to quantitatively explain the main features and implications of integrating EVs into the energy grid. Therefore, this study provides descriptive analysis of secondary data sourced from research articles and content analysis is employed as the main method to systematically gain a comprehensive analysis of empirical evidence. Findings from secondary sources used in this study are not statistically represented, but they provide rich understanding toward policy related to EV integration in smart cities.

\section{FINDINGS}

This section provides findings from the literature based on descriptive analyses of secondary sources.

\section{Energy Informatic for Sustainable Society}

Presently, Information System (IS) researchers are exploring how to counteract increased greenhouse gas emissions (GHG) toward supporting sustainability of energy system termed as energy informatics (Kossahl et al., 2012). Respectively, this current study belongs to the energy informatics domain as specified by Watson et al. (2010), since this study investigates how Information System (IS) components and actors are into a business models for integrating EVs to contribute toward energy sustainability of smart cities. According to Watson et al. (2010), Brandt et al. (2012) energy informatics is concerned with the role of Green Information Technology and Green IS initiatives can contribute to shaping the energy grid of the future.

Energy informatics further entails the analyzes, design, and deployment of sustainable systems to improve the productivity of energy supply and demand systems (Watson et al., 2010; Jnr, 2020; Jnr et al., 2020a,b). Thus, IS components deployed in EVs are envisioned to play a significant role on the quest for cities to attain a decarbonized and sustainable energy system (Kirpes and Becker, 2018). Therefore, to fully achieve a sustainable energy adoption in cities while transitioning to a low carbon energy system, decision makers need to employ renewable energy generation strategies to foster the integration of EVs in smart cities (Zame et al., 2018). Although, the integration of EVs has been highlighted in the literature, energy as a service business model as related to the integration of EVs has not been sufficiently explored.

\section{Background of Smart Cities and Sustainable Mobility}

Urban areas are inhabited by about half the world's inhabitants and its expected that in 2050 the population in these urban areas will increase to $\sim 2.6$ billion to 6.3 billion residents (Spickermann et al., 2014). Due to these urban challenges the topic of smart cities is globally gaining prominence (Anthony Jnr et al., 2020). Smart cities can bring future environmental, social, and financial benefits supported by technological innovations and digitalization (Ekman et al., 2019; Anthony Jnr, 2020c). Hence cities are becoming smart by implementing digital innovations in providing smart services that make life easier for citizens (Ekman et al., 2019; Anthony et al., 2020). Besides, a smart city is a social system that integrates business and technology into the society (Ekman et al., 2019). 


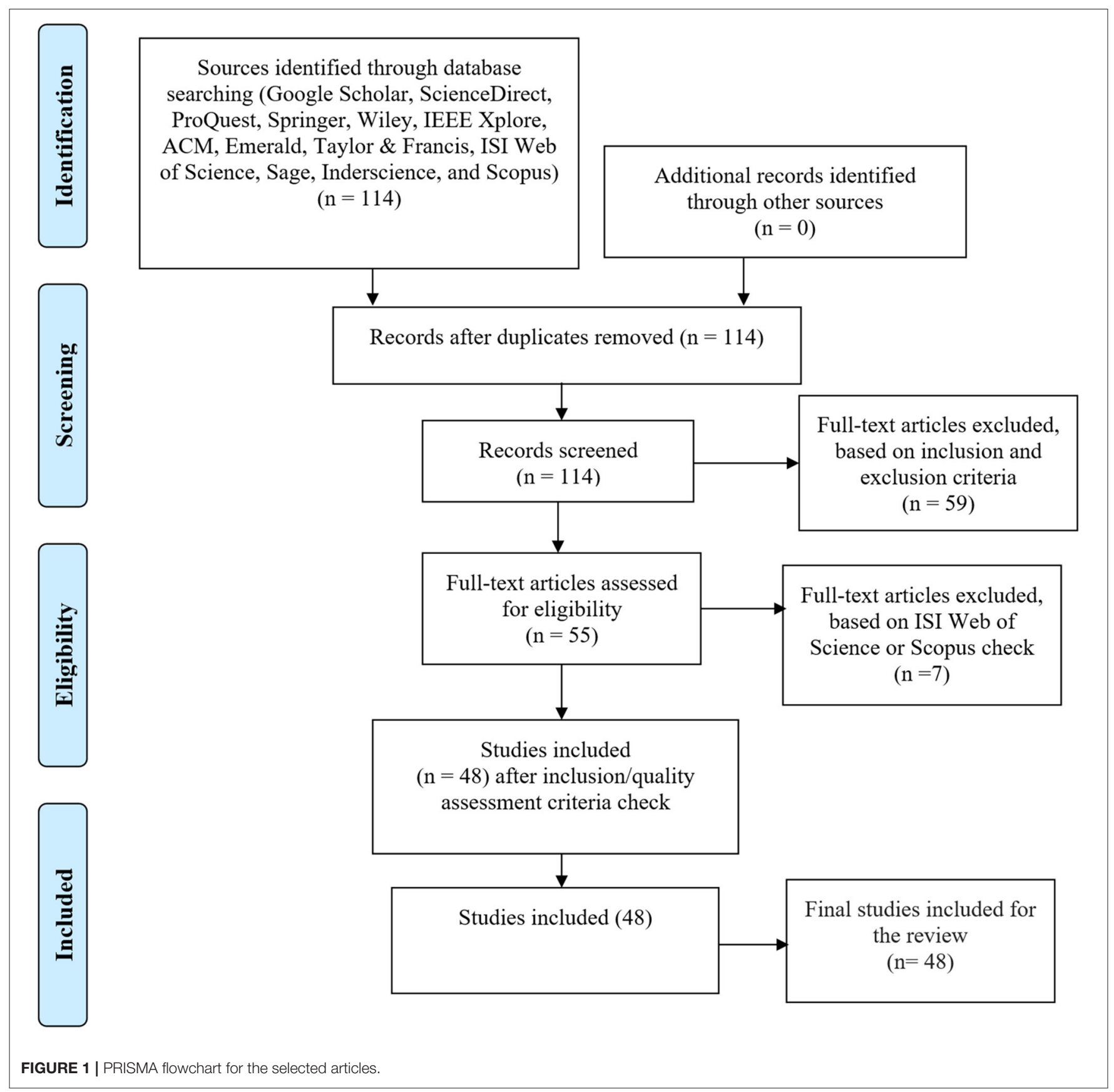

Smart city is a digital transformation where new actors arise and old actors may disappear due to the effect of deployment of disruptive technologies and new business models (Ekman et al., 2019; Anthony Jnr, 2020c). The fact that a substantial increase of the urban inhabitants is expected over the coming years leads to the postulation that the transport sector will be impacted within the next decades. As the number of vehicles in cities might significantly increase and pollution issues (Tcholtchev et al., 2012; Anthony and Petersen, 2019). Evidently, urban mobility is one of the main issues faced by cities. Therefore, there is need to improve the current urban mobility infrastructures by resolving the social, economic, and environmental constraints for a sustainable and competitive urban mobility systems (Spickermann et al., 2014). One possible alternative for achieving sustainable mobility in smart cities is the adoption of EVs such as electric bicycles, electric cars, segways, etc. (Tcholtchev et al., 2012).

\section{Role of Smart Grids and Sustainable Energy Systems}

Rapid growth and urbanization across the world and the increased need for energy related services necessitates the 
need to create more innovative business models in smart cities (Sanseverino and Sanseverino, 2018). Energy systems are deployed in smart cities such as smart appliances, energy sensors, smart meters, and smart grid. Smart sensors and meters can record and report energy consumption automatically and are one of the key enablers of sustainable energy transition (Cavoukian et al., 2010). The EU targets to install smart meters in $~ 80 \%$ of EU households in majority of member states as part of their energy policies aimed at supporting the balancing of electricity supply and demand within the energy grid. Thus, supporting climate change or sustainable energy policies (Zame et al., 2018). An example of a smart meter deployed in smart cities is the Advanced Metering Infrastructure (AMI) which supports bidirectional electricity flows utilizing a two-way communication allowing Energy Service Providers (ESPs) to receive electricity consumption data of residents (Vaidya and Mouftah, 2018). It also supports sending control signals or pricing back to customers in real time (Vaidya and Mouftah, 2018).

One of the energy systems in smart city is the smart grid which provide a transition toward a more sustainable energy system (Bellekom et al., 2016). In general, a smart grid is refers to as an electricity network that can autonomously integrate the actions and behavior of actors (such as producers and consumers), connected to it in order to achieve an economic, sustainable, and secure energy supplies (Rathnayaka et al., 2012). A smart grid deploys ICT with advanced energy infrastructure to achieve a bidirectional flow of information and electricity. It is self-healing as it quickly detects disruptions and rapidly recovers. It is also resistance to cyber-attacks and mitigates and improved energy quality, and facilities the interconnection to achieve plug-and-play (Rathnayaka et al., 2012). A smart grid employs a centralized generation and top-down distribution based on paradigm shift from the present energy network to a new digitalized grid (Giordano and Fulli 2012). A smart grid is envisioned as the next generation energy grid (Mustafa et al., 2014), and plays an important role in smart cities thereby facilitating smart decisions based on information to provide flexibility for energy usage for domestic use or for a city (Heo et al., 2014).

Smart grid aims to achieve energy resource management in a more efficient, resilient, and reliable manner (Cavoukian et al., 2010; Mustafa et al., 2014). The smart grid is different from the traditional energy grid as the traditional grid focused on the connections between the transmission, generators, and distribution (Rathnayaka et al., 2012; Anthony Jnr et al., 2020). Traditional energy grids are unable to manage complex energy scenarios. Thus, in the traditional energy grid users do not actively participate (Heo et al., 2014). The consumer only consumes the energy provided by the utility company and pay the electricity bill. In comparison, in the smart grid the energy consumer (typically called a prosumer), not only utilize energy but also generate and provide electricity back to the grid (Anthony et al., 2019). EVs are recognized as a main contributed in the realization of the smart grid vision since their batteries can possibly be utilized as a flexible electricity storage (Mustafa et al., 2014). Thus, the smart grid can manage EV connection, charging, and incorporating cleaner sources of energy into the energy grid thereby providing consumer control over energy cost and usage (Cavoukian et al., 2010).

\section{Role of EVs in Smart Cities}

The need to increase environmental concerns and reduce oil supply has sprung the need for research toward the electrification of the transportation sector, and technological development have advanced the rapid integration of EVs in cities. The term electric vehicle refers to vehicles deploying electric motor(s) for propulsion, comprising both rail and road vehicles, underwater and surface vessels, as well as electric aircrafts (Eider et al., 2017). EV aids electricity management as the batteries can store energy to be used as reserve of energy when the EVs are idle. Thus, EVs can serve as energy storage facilities by providing the needed flexibility to the smart grid operator. By providing energy back to the grid, thereby serving as a distributed energy source. Accordingly, EVs can be leveraged by network operators to enhance renewable energy usage for self-healing or to provide supplementary energy services, so as to lessen the dependency on diesel source generators (Eider et al., 2017). Thus, lessening electricity fluctuations and inefficiencies faced in today's grid. Similarly, for energy suppliers the electrification of vehicles offers off-peak supply and demand, which lessens the burden on the energy grid during peak hours (Dijk et al., 2013).

EVs can support additional services such as power factor regulation, voltage support, renewable energy tracking, active harmonic filtering, peak shaving, and load balancing. Additionally, in case of power outage EV can be utilized as an emergency backup source in residential area (Li et al., 2017). Conversely, EV load within the energy grid can upsurge energy prices up, and change energy generation resulting in an increased $\mathrm{CO}_{2}$ emission. Additionally, resulting to uncontrolled charging and high penetration which threatens the sustainability of electricity distribution networks (Eider et al., 2017). As highlighted by Dijk et al. (2013) EVs may become the connection between energy and the transportation sectors. Additionally, the integration of EVs in smart cities provides large amounts of data that can be utilized to create new opportunities and business models for enterprises improving their competitive positions and business strategies of companies involved in EV adoption (Dijk et al., 2013).

\section{Electric Vehicles as Flexibilities in Smart Cities}

Climate change and the increased need for energy are driving policy makers to explore how to improve the adoption of sustainable services and products (Kotilainen et al., 2017). Transportation and energy both contribute to 49 percent of total greenhouse gases released to the atmosphere. Findings from the literature revealed that EVs has been sustainable adopted using Renewable Energy Sources (RES) and Vehicle to Grid (V2G) deployment (Kotilainen et al., 2017). EVs can offer pervasive services in the form of energy demand response via the EV batteries which store electrical energy. Thus, EVs can be used for driving/mobility purposes as well as for energy services making the batteries as asset (Weiller and Neely, 2014). Evidently, EV can contribute toward the transition to a sustainable energy demand supply system for the energy grid where peak and 
baseload demand is managed in association with supply sources from renewables. EVs provides the opportunities to provide a Vehicle-to-Grid (V2G) or Grid-to-Vehicle (G2V) capabilities.

$\mathrm{G} 2 \mathrm{~V}$ involves the flow of electric energy from the energy grid to the EV (Anthony Jnr et al., 2020) or simply the charging of the EV battery from the energy grid (Brandt et al., 2012), whereas V2G involves the return of energy from the EV battery into the energy grid. This helps to achieve a synergy between the electricity system and EV fleets (Hinz et al., 2015). V2G allow the EV to be able to function as energy storage that could be charged at night and can displace consumer's load during daytime when the vehicle is not in use (Brown et al., 2010). EV owners can charge their EV battery when energy cost is low and feed in the energy grid when there is high prices and high demand (Hinz et al., 2015). However, V2G entails two-way transmission of energy between the EV and the charging station, a feature which only exists in some manufactured EVs such as the Mitsubishi iMiEV but may not be available for other standard EVs (Weiller and Neely, 2014). As EVs can charge at a rate of about $50 \mathrm{~kW}$ and discharges via V2G technologies at a rate restricted to about 3.7 $\mathrm{kW}$ on a standard European energy grid or intermediate charging of about $20 \mathrm{~kW}$ (Weiller and Neely, 2014).

Besides, the integration of V2G involves deployed EV to be equipped with a link to the energy grid for flow of electrical energy, deployment of communication control by the grid operator, and lastly vehicle on-board control and metering systems (Rathnayaka et al., 2012; Vaidya and Mouftah, 2018). The on-board metering sensors will facilitate tracking of energy flows from and to the EV. This will help for better energy resources management and provides opportunity for arbitrage (Eider et al., 2017), for EV owners and EV fleet owners, or EV charging stations to get money by trading energy power to the grid (Brown et al., 2010; da Silva and Santiago, 2019). This also helps to mitigate peak demand shocks within smart cities and offers the grid operator with a cost-effective medium to balance supply and demand, relying on EV batteries as energy buffers or storage facilities (Eider et al., 2017).

As pointed out by Eider et al. (2017) EVs are often faced with electricity transmission and/or DC/AC conversion losses. Thus, electricity losses should be considered when EVs receives and provide energy services through V2G. Additionally, the integration of EVs for V2G capabilities enabling the possibility that stored energy could be feed back to the energy grid, requires that $\mathrm{EV}$ chargers are potential sources for power quality disturbances and harmonics (Brown et al., 2010). Moreover, there may be associated risks involved when integrating V2G capabilities of EVs into the energy grids which may lead to significant increase of electricity prices from the energy grid. This is mostly the case for real-time pricing, where the local energy production does not match local energy demand. This risk is also related with the current price of electricity from the energy grid, leading to risk of peaks of electricity demanded from the microgrid (da Silva and Santiago, 2019).

Overall, EVs have a large potential for decreasing $\mathrm{CO}_{2}$ emissions and fossil fuels consumption. EV owners can now generate their own electricity directly from solar photovoltaic panels or other Renewable Energy Sources (RES), installed residentially. The generated electricity from RES can be commercialized with the energy grid or consumed by the residential owner. Such flexibility support EV owner to become an energy producers and consumers, termed as a prosumer (energy producer + energy consumer) (da Silva and Santiago, 2019). Thus, EVs connected to the grid can basically contribute as loads on demand or as generators. However, in smart cities for the fully potentials V2G to be achieved several EVs needs to be aggregated as fewer EVs may only have little impact on the energy grid frequency (Brandt et al., 2012). Evidently, there have been several studies on EV aggregation schemes, but only fewer studies have provided an extensive business model on the integration of EVs to implement energy as a service eco-system in smart cities.

\section{Proposed Energy as a Service Business Model in Smart Cities}

A business model comprises of a set of activities an enterprise or group of organizations performs, how they perform the activities, and when the activities are performed. It also entails how resources are used to perform these activities by the organization(s) to create lower cost, value added services and products to customers and stakeholders (Kley et al., 2011). In the context of this study a business model can be an ecosystem that comprises of technical components and stakeholders' capabilities and processes which specifies the services and functions that enabling cities to become smart cities. The business model aims to manage and aggregate information from a wide variety of stakeholders or actors as well as components (i.e., energy devices and energy sensors, energy assets, etc.), required to enable energy management and finally presentation of data as information to all stakeholders involved in the energy system within smart cities (Zuccalà and Verga, 2017). Accordingly, based on findings from prior studies (Dijk et al., 2013; Mustafa et al., 2014; Kirpes et al., 2019) the energy as a service business model for EV integration in smart cities is proposed as presented in Figure 2.

Figure 2 depicts the actors and components in the energy as a service business model for EV integration in smart cities, where each of the components are used by the actors in achieving a sustainable energy system in smart cities. The components work together for successful EV integration in smart cities to help achieve decarbonization strategies, reducing operational and maintainable cost of EV (Dijk et al., 2013). The interaction of the actors and connection of the components can help to develop EV adoption in smart cities which is important for harmonizing the interaction between the various energy systems and stakeholders, e.g., grid operators, car manufactures, charging station operators, energy suppliers, e-mobility service providers, and EV users (Kirpes et al., 2019). Next, each of the components and actors are described in Table 1.

Accordingly, Table 1 describes the actors and components in the energy as a service business model in smart cities. The DSO is the energy grid operator or Transmission System Operator (TSO) who offers the grid technologies either directly to the $\mathrm{EV}$ fleet operator or to the charging station operator, where both actors are provided with electricity power from the energy supplier. The charging station operator mostly provided charging 


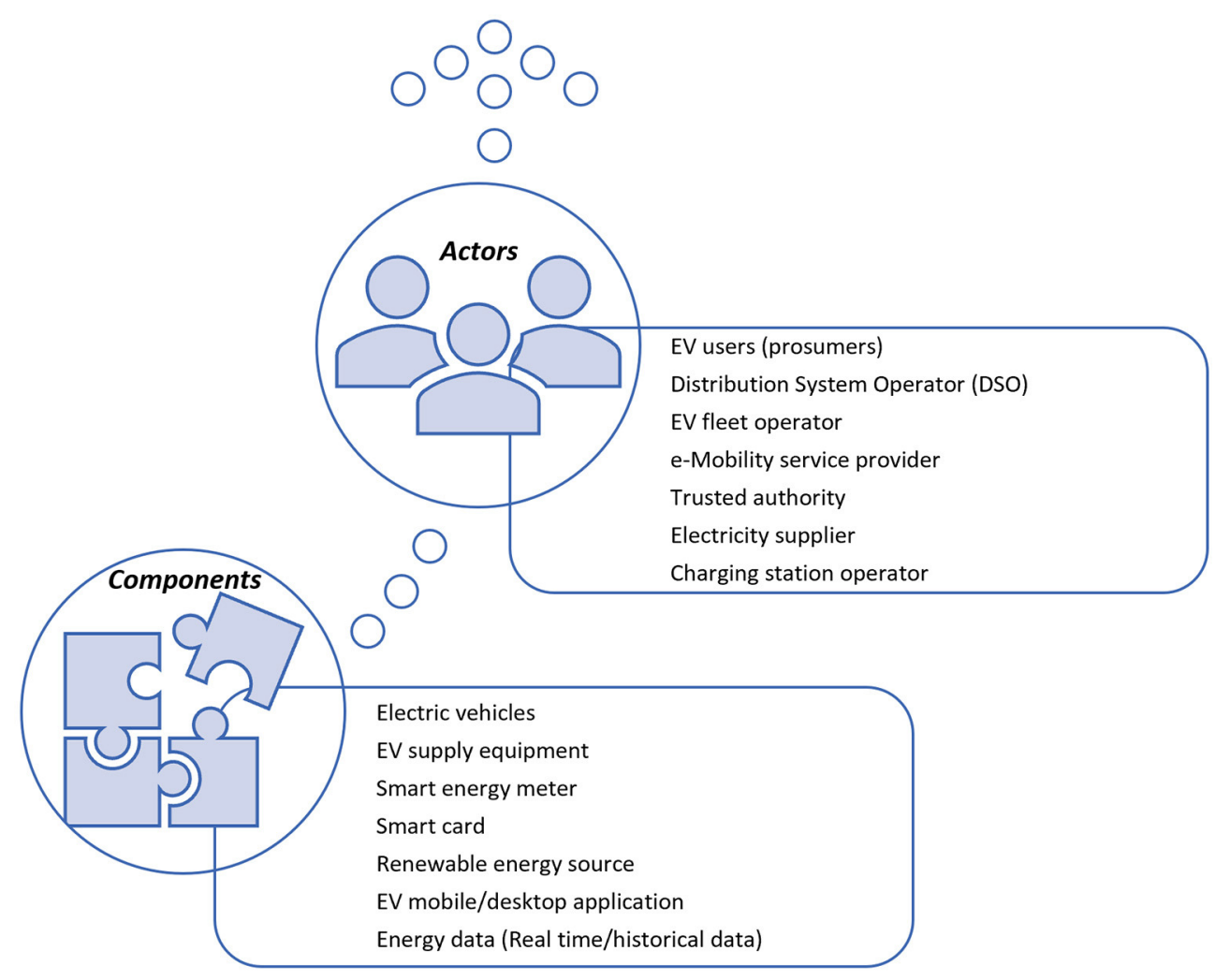

FIGURE 2 | Proposed energy as a service business model for EV integration in smart cities.

infrastructures to EV user and enters into a mutual agreement with the eMobility service provider (Kirpes et al., 2019). Thus, digitization and synergies among all actors and components presented in proposed energy as a service business model in smart cities not only including stakeholders from the energy sectors but may also other domains such as real time/historical data which are important to manage transportation in smart cities (Kirpes et al., 2019).

\section{Optimization of Electric Vehicle Charging Stations}

To realize sustainable energy transition, efficiently energy system, and zero-emission vehicles in smart cities the integration of EVs are envisioned to play an essential role (Kirpes et al., 2019). In smart cities EVs can be charged based on demandside management which refers to the option to plan EV charging during low demand on the energy grid (Dijk et al., 2013). Presently, EV charging can be performed in several ways as EVs can utilize an off-board or on-board charger or use an inductive charging while parked via Inductive Power Transmission (IPT) infrastructure (Eider et al., 2017). EV batteries are charged by means of an onboard charger and Electric Vehicle Supply Equipment (EVSE), also referred to as charging stations. EVSEs can be installed at residential premises, parking lots of commercial buildings, and along roadside charging facility (Li et al., 2017). EV connected to the energy grid mostly consume from 3 to $50 \mathrm{~kW}$ energy but can also consume up to $100 \mathrm{p} \mathrm{kW}$ of energy at fast-charging stations e.g., as used by superchargers (Weiller and Neely, 2014).

Prior studies in the literature explored smart charging of EVs which comprises of concepts facilitated by ICT to reduce the impact of EV charging operations on the energy grid from an economic and energetic perspective (Kirpes et al., 2019). Smart charging is enabled by ICT to reduce the impact of EV charging on the energy system on economic and energetic level (Kirpes and Becker, 2018). In smart cities the charging stations are geographically dispersed but integrated into a single network. All connected charging station are intelligently setup to provide data emitted on their electricity costs, individual status, geographical location, energy consumption, available voltage, power type, charging speed, plug type, cable available, and locker available (Karpenko et al., 2018), which is send to the EV mobile/desktop application used by the EV user (Tcholtchev et al., 2012). The classification of the charging facilities for EVs are shown in Figure 3.

Figure 3 depicts the different types of charging facilities for EVs. One of such charging stations is the individual stations which is deployed in residential areas or located in individual homes capable of charging a single EV. This comprises of single charging station for private or home garages and public charging. Also, there are EV charging stations installed in parking lots which comprises of public and private EVSEs within close 
TABLE 1 | Actors and components in the energy as a service business model.

\begin{tabular}{|c|c|}
\hline Actors and components & Description \\
\hline EV users (prosumers) & $\begin{array}{l}\text { An EV user who is in charge for paying for the EV charging sessions. The EV user drives the EV after charging and } \\
\text { may also provide energy back to the energy grid as a prosumer. }\end{array}$ \\
\hline Distribution System Operator (DSO) & $\begin{array}{l}\text { The role of the DSO is to increase the inflows of energy from RES as well as ensure. That certain qualities are } \\
\text { adhere to when amidst the energy demand and supply. }\end{array}$ \\
\hline Electric vehicles & This is a battery-powered vehicle which includes e-cars, e-scooters, e-bikes, e-buses, and e-railway. \\
\hline EV supply equipment & A device that connects EVs to the energy grid, measures the electricity utilized by the EV. \\
\hline EV fleet operator & $\begin{array}{l}\text { The EV fleet operators manage the fleet of EVs by optimizing charging in relation to costs, proportion of renewable } \\
\text { energy uses, energy grid, and battery-friendliness (e.g., to sustain the durability and health of the battery). The fleet } \\
\text { operators are presently evolving as a main contributor that influence the directions of EV commercialization and } \\
\text { development. }\end{array}$ \\
\hline e-Mobility service provider & $\begin{array}{l}\text { The e-Mobility service provider provides different EV related as services to the EV customers, such as booking, } \\
\text { parking, billing process, etc. }\end{array}$ \\
\hline Smart energy meter & $\begin{array}{l}\text { This is an advanced metering device that measures EV user's electricity usage and production in the EV user's } \\
\text { residence or charging station. }\end{array}$ \\
\hline Smart card & $\begin{array}{l}\text { This is a tamper-proof hardware that records and retains EV user's personal data, employing secured techniques } \\
\text { such as cryptographic keys, hash algorithms, etc. }\end{array}$ \\
\hline Renewable energy source & An energy source from solar panel, wind turbine, etc. located at the EV user's residence or charging station. \\
\hline Trusted authority & $\begin{array}{l}\text { This is usually a trusted body such as an electricity market regulator that initializes and monitors the entire energy } \\
\text { system and certifies other stakeholders using public keys to ensure transparency and authentication. }\end{array}$ \\
\hline Electricity supplier & This is a utility firm that oversees supplying electricity to its users or customers that consume electricity. \\
\hline Charging station operator & $\begin{array}{l}\text { Mostly provides charging facilities to the EV user ensuring a bilateral agreement with the eMobility service provider. } \\
\text { The charging station operator also aims to increase EV charging services and net profit via deployment of ICT to } \\
\text { lessen the impact of EV charging operations on the energy grid from an economic viewpoint. }\end{array}$ \\
\hline EV mobile/desktop application & $\begin{array}{l}\text { The EV user utilize this application in their mobile devices or personal devices to select a charging station, for } \\
\text { example based on greenness or cheapest indicators on the planned journey route. Also, the application provides } \\
\text { information related to EV use within the cities. It provides data on number of EV charging connectors, EV charging } \\
\text { type, status of EV charging connector, etc.) as related to EV charging stations. }\end{array}$ \\
\hline Energy data (Real time/historical data) & $\begin{array}{l}\text { Encompasses data from smart energy meters, EV energy on energy produced and consumed, journey } \\
\text { information, parking, and charging. Also, data on sensors and controllers in the EV, EV battery-health service, and } \\
\text { Battery State of Charge (SoC). The data is used by the on-board control and metering systems such as battery } \\
\text { health suggestions, EV usage, and advanced charging services like dynamic prices, reservation, and grid-friendly } \\
\text { charging or green charging via RES. }\end{array}$ \\
\hline
\end{tabular}

charging or green charging via RES.

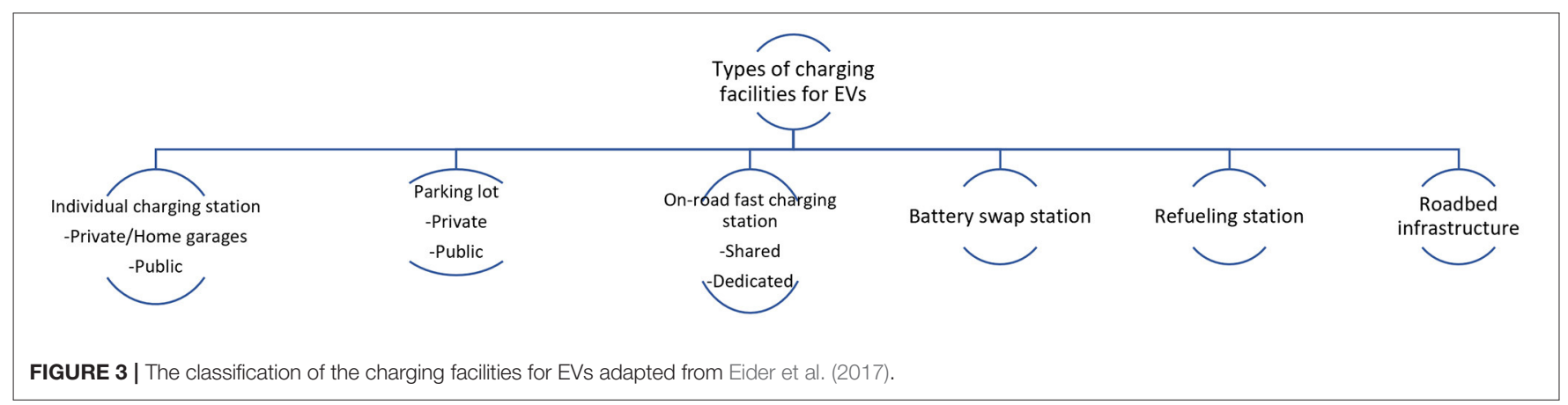

physical proximity. The public EV charging stations are mainly open to any EV, whereas the private EV charging provide access only to an explicit fleet or types of EVs. For example, EVs owned by a particular company. Another type of charging is the on-road charging stations which are deployed as relays for EVs on long distance journeys. The on-road type employs fast charging station which are dedicated and shared. Thus, EVs can generally charge their battery at the highest rate possible to reduce the delay. Accordingly, roadbed technologies are now provided for EVs based on wireless power transfer solutions (Eider et al., 2017).

Additionally, other types of charging facilities are battery swap stations where the EV user changes battery for newer charged battery for a subsidized fee from the manufacturer based on a stipulated agreement from the EV manufacturer. This is done when the EV us being used for a long-distance journey. The last two charging stations are the refueling station and roadbed infrastructure (Eider et al., 2017). The EV refueling station are 
used by EVs that have converters on board that plug into a high-capacity appliance outlet or standard electrical or outlet. Currently, these refueling stations can facilitate faster charging at higher currents and voltages as compared to residential charging infrastructures. Lastly, the roadbed infrastructure comprises of contact-less inductive power transfer system for specific EVs.

\section{Barriers and Recommendations for EV Integration Barriers That Impends the Integration of EV in Smart Cities}

For cities to achieve a sustainable low carbon economy there is need for innovative and adoption of a range of carbon neutral technologies for providing sustainable energy and other environmental services (Anthony et al., 2019). Prior literature on sustainable energy production and storage suggest the integration of EVs can support sustainable development of smart cities (Anthony Jnr et al., 2020). In several countries such as Norway etc. EVs were subsidized and exempted from paying for road tax (Hinz et al., 2015; Zame et al., 2018), and adequate parking spaces are mostly reserved in the city centers for purely battery powered EVs without any time constraint (Lieven, 2015). But, while the integration of EVs are increasing around the world, major barriers still hinder the fully integration of EVs in smart cities (Kirpes and Becker, 2018). Issues such as procurement cost, inadequate awareness of governmental incentives, battery range, taxation policies, and charging interoperability are mitigating against the adoption of EVs (Kotilainen et al., 2017).

In relation to price of $\mathrm{EV}$ findings from the literature (Hinz et al., 2015), highlighted the importance of price which includes EV purchase price and EV charging costs. Besides, the price difference between EV original purchase price and an internal combustion engine vehicle is still extensive. Even though EV maintenance cost is less expensive, the initial money needed is the purchase of EV is quite high (Kotilainen et al., 2017). Hence, EVs integration is faced with techno-economic and societal challenges, varying from infrastructural requirements to users doubts concerning EV price, charging time, non-ubiquity of EV charging stations (Li et al., 2017), safety, reliability, distance range, maintenance service availability, and battery life durability (Rodríguezet al., 2015; Karpenko et al., 2018). Although newly developed battery technologies provide more power, longer ranges, and a reduced recharging time (e.g., the new waterbased battery by General Electric and lithium-ion technology by Toyota) (Zame et al., 2018).

In addition, there are concerns that with increase in the EV market, the impact of EVs usage on the energy grid may result to adverse impacts such as increased losses, peak loading, voltage deviations or unbalance, and need for further network reinforcements (Li et al., 2017). This may lead to high stress on distribution systems of the smart grid. Due to increased energy consumption on the energy network during peak hours (Li et al., 2017). Although integration of EV delivers numerous benefits to the smart grid and enables consumers to be prosumers. In smart cities energy systems has increasingly become susceptible to a wide range of security issues and cyber-threats. Basically, these energy systems such as smart grid infrastructures and EVs collects citizens personal data that is utilized for several purposes such as real-time energy pricing and energy demand response. However, there is need to address data security and privacy issues (Vaidya and Mouftah, 2018).

\section{Recommendations for Integration of EV in Smart Cities}

The emerging prospect for EV to revolutionize both the energy and transportation sector over the next the coming years is immense. The integration and use of EVs contributes to lessen air-pollution in urban areas, decreases noise, and potentially uses environmentally friendly electricity from RES to charge the batteries. But, to achieve a smooth integration of EVs in smart cities there are technical, economic, and social issues that should be addressed. Technical issues related to infrastructural limitations within the different areas, economic, and regulatory setbacks need to be considered. As the continually evolving EV market also requires legal frameworks and innovative business models that can conform with future technological innovations (Kirpes al., 2019). Another social-techno challenge relate to compatibility and standardization polices. Thus, researchers such as Brown et al. (2010) argued that standardization can help promote the adoption of EV in cities.

Therefore, compatibility and standardization across EVrelated infrastructure and technologies will be a crucial factor that will significantly influence the integration of EVs in smart cities. EV standardization is not only relevant for the mobility sector, but is also concern with how electricity is generated, stored, and distributed within the smart grid through V2G technologies (Brown et al., 2010). New standards and regulations can be put in place for EV related systems, infrastructures, and designs to promote integration of EV by establishing consistent and compatible design within the energy systems (Brown et al., 2010). Such polices can be directed to ensure that electricity generation from EVs should originate from low-carbon and cleaner sources (Brown et al., 2010). Additionally, battery management should be enhanced to increase the driving range and decrease charging impact on the smart grid (Kotilainen et al., 2017). The driving behavior of EV users and routing may be incentivized to further contribute to reducing battery discharge time (Eider et al., 2017).

EV fleet management firms should employ an optimized fleet routing and charging to contribute toward EV and smart grid integration RES utilization (Eider et al., 2017). EV charging stations should be managed in co-ordination with other actors as seen in the proposed business model (see Figure 2). Another area of concern is data security and privacy for EV user as a lack of security might impact consumers participation as prosumers within the smart grid (Giordano and Fulli, 2012). Data security should employ methods to ensure confidentiality and integrity of data and availability of ICT related systems deployed within EVs (Vaidya and Mouftah, 2018). Ensuring data security helps to reduce leaking of customers personal information, individual behaviors, daily activities, etc. Privacy is concern with the interests, rights, and values of EV users. As stated by Vaidya and Mouftah, (2018) data privacy should ensure privacy of personal data, privacy of the individuals, privacy of private behavior, 
and privacy of private communications. Similarly, data privacy emphasizes the consumer's ability to manage the use, collection, and dissemination of his/her personal data.

\section{DISCUSSION AND IMPLICATIONS}

\section{Discussion}

Over the decade the use of EVs in cities has increased mostly due to an efforts to mitigate climate change, government incentives for $\mathrm{EV}$ related to international competitiveness and economic stimulus, as well as a pressure by governments to promote sustainable energy production and usage (Brown et al., 2010). The integration of EV in smart cities supports sustainable energy more when RES is used to charge the EV battery and $\mathrm{EV}$ is employed for demand response via V2G connection to balance peak-off peak consumption to further assist in demand smoothing (Brown et al., 2010; Kotilainen et al., 2017). Overall, findings from this study show that prior works have explored the social, institutional, and regulatory issues relating to adoption of EVs in smart cities and in particular toward improving the technological development of smart grids. Also, literature addressing integration of EVs has primarily considered technical issues such as the optimal range of EV or EV charging facilities, adoption/acceptance of EVs to decrease greenhouse gas emission, and EV sales predictions (Lieven, 2015).

Accordingly, this study employs secondary data to explore and provide a business policy viewpoint on EV integration in smart cities. This study also presents an energy as a service business model in smart cities. The proposed business model depicts that the integration of EVs is highly dependent on the collaboration of actors or stakeholders and components. Findings from this study also suggest that EV usage have proved to be one of the main practices toward lessening $\mathrm{CO}_{2}$ emission for sustainable energy and mobility. As EVs allow for synergies with a smart grid based on clean energy from RES (Schuh et al., 2013). On the one side, the integration of EVs in smart cities has emerge as a great challenge due to several issues as discussed in section Barriers and Recommendations for EV Integration, but it also provides an opportunity to develop the smart grid.

\section{Implications for Policy and Practice}

Given the increased demand for electricity resulting from rapid economic growth, issues related to environmental protection, climate change, and sustainable development have become important (Lin et al., 2013). Hence, it is crucial to abate carbon emissions and conserve energy by promoting employing environmentally friendly practices (Jnr, 2020; Jnr et al., 2020a,b). One of the environmentally friendly practices that can effectively decrease $\mathrm{CO}_{2}$ emissions is the utilization of renewable energies, such as solar, geothermal heat, wind, tides, and rain to replace the combustion of fossil fuels (Lin et al., 2013). Additionally, the integration of EVs can contribute toward sustainable energy transition of cities. However, the issues relating EV integration policy have not been discussed considering the business model. Thus, the lack of research studies on business model approach for EV integration will make it difficult to specify the actors and components involved within smart cities toward effective development of the smart grid systems. In this context, this study provides a business-oriented approach to fulfill the vision of EV integration in urban context.

As cities now use EVs for environmentally friendly transportation and energy source to efficiently deliver green, secure, and economic energy supplies (Zame et al., 2018). Additionally, this study explicitly considers the prospects for a new business model innovation to support EV integration. Although prior studies (Brandt et al., 2012; Dijk et al., 2013; Anthony and Petersen, 2019; Jnr et al., 2020b), explored different EV adoption scenarios, such as eMaaS concepts, they do not explicitly investigate strategies for different actors and components or issues that impacts the integration of EVs in urban context. This research provides a business model (see Figure 2) to support policymakers in the energy sector to enhance their EV implementation, policies outcomes and quality of their environmental initiatives. By integrating this model into their current policy planning they can improve collaboration of stakeholders involved in EV adoption in smart cities.

This article also sought to contribute to the literature on energy sustainability by identifying barriers that impacts EV integration and to provide recommendations on how industry, researchers, and policymakers can effectively improve integration of EVs. As highlighted by Lin et al. (2013) this study contributes to advance the social economy of businesses involves in eMobility in urban context thereby providing a resource-saving and green society where energy supply is efficient, clean, secure, and reliable. Practically, this study contributing to sustainable development of energy production and use by enabling the optimal use of RES toward improving the energy grids' capability for improved allocation of electricity. The business model can be employed as a policy tools toward developing a roadmap improve the integration of EVs in smart cities.

\section{CONCLUSION}

The reduction of $\mathrm{CO}_{2}$ emissions is a crucial goal particularly in the transport sector as this sector contributes roughly to onefourth of the total global greenhouse gas emissions, which are projected to increase from 23 to 50 percent by 2030 (Wang et al., 2016). Thus, reducing $\mathrm{CO}_{2}$ emission and increasing the energy efficiency of vehicles by exploiting sustainable energy strategies in transportation sector is viewed as important in an effort to lessen carbon footprint the emergence of EVs provides ample opportunity to improve sustainable mobility and energy. EV can provides opportunities for dispatch of storage units and load control making RES such as solar PV and wind more pertinent to the energy grid (Zame et al., 2018). Accordingly, this study proposes an energy as a service business model to explore how EVs can contribute to achieve sustainable energy in smart cities. Additionally, this study explores the emerging role of energy informatic, role of smart grids and sustainable energy systems, benefits of integrating EV within the energy grid as flexibilities and EV's implications for providing incentives to its users. 
Moreover, findings discuss the optimization of electric vehicle charging stations, barriers, and recommendations for EV integration in smart cities. The study has some limitations. Firstly, only secondary data from the literature was used in this study. Secondly, the actors and components in the proposed model were not validated. Lastly, this study is mainly based on the business perspective and the technical viewpoint of EV integration was not explored. These limitations can provide a road map for future study of on EV integration. Further work may focus on conducting a case study to follow-up investigation on EV adoption, particularly because the number of stakeholders involved in EV integration in smart cities are increasing.

\section{REFERENCES}

Anthony Jnr, B. (2020a). Smart city data architecture for energy prosumption in municipalities: concepts, requirements, and future directions. Int. J. Green Energy 17, 827-845. doi: 10.1080/15435075.2020.1791878

Anthony Jnr, B. (2020b). "Applying enterprise architecture for digital transformation of electro mobility towards sustainable transportation," in Proceedings of the 2020 on Computers and People Research Conference (Nuremberg), 38-46.

Anthony Jnr, B. (2020c). Managing digital transformation of smart cities through enterprise architecture-a review and research agenda. Enterp. Inf. Syst. 15, 299-331. doi: 10.1080/17517575.2020.1812006

Anthony Jnr, B. (2020d). Implications of telehealth and digital care solutions during COVID-19 pandemic: a qualitative literature review. Inform. Health Soc. Care 46, 68-83. doi: 10.1080/17538157.2020.1839467

Anthony Jnr, B., and Abbas Petersen, S. (2020). Examining the digitalisation of virtual enterprises amidst the COVID-19 pandemic: a systematic and metaanalysis. Enterp. Inf. Syst. 15, 617-650. doi: 10.1080/17517575.2020.1829075

Anthony Jnr, B., Abbas Petersen, S., Ahlers, D., and Krogstie, J. (2020). API deployment for big data management towards sustainable energy prosumption in smart cities-a layered architecture perspective. Int. J. Sustain. Energy 39, 263-289. doi: 10.1080/14786451.2019.1684287

Anthony, B., and Petersen, S. A. (2019). "A practice based exploration on electric mobility as a service in smart cities," in European, Mediterranean, and Middle Eastern Conference on Information Systems (Cham), 3-17.

Anthony, B., Petersen, S. A., Ahlers, D., Krogstie, J., and Livik, K. (2019). Big dataoriented energy prosumption service in smart community districts: a multicase study perspective. Energy Inform. 2, 1-26. doi: 10.1186/s42162-019-0101-3

Anthony, B., Petersen, S. A., and Helfert, M. (2020). "Digital transformation of virtual enterprises for providing collaborative services in smart cities," in Working Conference on Virtual Enterprises (Cham), 249-260.

Bedogni, L., Bononi, L., Di Felice, M., D’Elia, A., Mock, R., Montori, F., et al. (2013). "An interoperable architecture for mobile smart services over the internet of energy," in 2013 IEEE 14th International Symposium on "A World of Wireless, Mobile, and Multimedia Networks"(WoWMoM) (Madrid), 1-6.

Bellekom, S., Arentsen, M., and van Gorkum, K. (2016). Prosumption and the distribution and supply of electricity. Energy Sustain. Soc. 6, 1-17. doi: 10.1186/s13705-016-0087-7

Bohnsack, R., Pinkse, J., and Kolk, A. (2014). Business models for sustainable technologies: exploring business model evolution in the case of electric vehicles. Res. Policy 43, 284-300. doi: 10.1016/j.respol.2013.10.014

Brandt, T., Wagner, S., and Neumann, D. (2012). "Road to 2020: IS-supported business models for electric mobility and electrical energy markets," in Thirty Third International Conference on Information Systems (Orlando, FL), 1-10.

Brown, S., Pyke, D., and Steenhof, P. (2010). Electric vehicles: the role and importance of standards in an emerging market. Energy Policy 38, 3797-3806. doi: 10.1016/j.enpol.2010.02.059

Cavoukian, A., Polonetsky, J., and Wolf, C. (2010). Smartprivacy for the smart grid: embedding privacy into the design of electricity conservation. Identity Inf. Soc. 3, 275-294. doi: 10.1007/s12394-010-0046-y

\section{AUTHOR CONTRIBUTIONS}

BA contributed in conducting the review and drafting the manuscript.

\section{FUNDING}

This publication is a part of the +CityxChange (https:// cityxchange.eu) smart city project under the Smart Cities and Communities topic that was funded by the European Union's Horizon 2020 Research and Innovation Programme under Grant Agreement No. 824260.

da Silva, H. B., and Santiago, L. P. (2019). “Optimal energy trading policy for solarpowered microgrids: a modeling approach based on plug-in hybrid electric vehicles," in Smart and Digital Cities (Cham), 251-273.

Dijk, M., Orsato, R. J., and Kemp, R. (2013). The emergence of an electric mobility trajectory. Energy Policy 52, 135-145. doi: 10.1016/j.enpol.2012.04.024

Eider, M., Sellner, D., Berl, A., Basmadjian, R., de Meer, H., Klingert, S., et al. (2017). "Seamless electromobility," in Proceedings of the Eighth International Conference on Future Energy Systems (Shatin),316-321.

Ekman, P., Röndell, J., and Yang, Y. (2019). Exploring smart cities and market transformations from a service-dominant logic perspective. Sustain. Cities Soc. 51:101731. doi: 10.1016/j.scs.2019.101731

Giordano, V., and Fulli, G. (2012). A business case for smart grid technologies: a systemic perspective. Energy Policy 40, 252-259. doi: 10.1016/j.enpol.2011.09.066

Heo, T., Kim, K., Kim, H., Lee, C., Ryu, J. H., Leem, Y. T., et al. (2014). Escaping from ancient Rome! applications and challenges for designing smart cities. Trans. Emerg. Telecomm. Technol. 25, 109-119. doi: 10.1002/ett.2787

Hinz, O., Schlereth, C., and Zhou, W. (2015). Fostering the adoption of electric vehicles by providing complementary mobility services: a two-step approach using Best-Worst Scaling and Dual Response. J. Bus. Econ. 85, 921-951. doi: 10.1007/s11573-015-0765-5

Jnr, B. A. (2020). Examining the role of green IT/IS innovation in collaborative enterprise-implications in an emerging economy. Technol. Soc. 62:101301. doi: 10.1016/j.techsoc.2020.101301

Jnr, B. A., Majid, M. A., and Romli, A. (2020a). A generic study on Green IT/IS practice development in collaborative enterprise: insights from a developing country. J. Eng. Technol. Manag. 55:101555. doi: 10.1016/j.jengtecman.2020.101555

Jnr, B. A., Petersen, S. A., Ahlers, D., and Krogstie, J. (2020b). Big data driven multitier architecture for electric mobility as a service in smart cities. Int. J. Energy Sect. Manag. 14, 1023-1047. doi: 10.1108/IJESM-08-2019-0001

Karpenko, A., Kinnunen, T., Madhikermi, M., Robert, J., Främling, K., Dave, B., et al. (2018). Data exchange interoperability in IoT ecosystem for smart parking and EV charging. Sensors 18:4404. doi: 10.3390/s18124404

Kirpes, B., and Becker, C. (2018). "Processing electric vehicle charging transactions in a blockchain-based information system (pp. Pres-4)," in Twenty-Fourth Americas Conference on Information Systems (New Orleans, LA), 1-5.

Kirpes, B., Danner, P., Basmadjian, R., De Meer, H., and Becker, C. (2019). E-mobility systems architecture: a model-based framework for managing complexity and interoperability. Energy Inform. 2, 1-31. doi: 10.1186/s42162-019-0072-4

Kley, F., Lerch, C., and Dallinger, D. (2011). New business models for electric cars-a holistic approach. Energy Policy 39, 3392-3403. doi: 10.1016/j.enpol.2011.03.036

Kossahl, J., Busse, S., and Kolbe, L. M. (2012). "The evolvement of energy informatics in the information systems community-a literature analysis and research agenda," in ECIS 2012 Proceedings (Barcelona).

Kotilainen, K., Mäkinen, S. J., and Valta, J. (2017). "Sustainable electric vehicleprosumer framework and policy mix," in 2017 IEEE Innovative Smart Grid Technologies-Asia (ISGT-Asia) (Auckland), 1-6. 
Li, B., Kisacikoglu, M. C., Liu, C., Singh, N., and Erol-Kantarci, M. (2017). Big data analytics for electric vehicle integration in green smart cities. IEEE Commun. Mag. 55, 19-25. doi: 10.1109/MCOM.2017.17 00133

Lieven, T. (2015). Policy measures to promote electric mobilitya global perspective. Transp. Res. Part A Policy Pract. 82, 78-93. doi: 10.1016/j.tra.2015.09.008

Lin, C. C., Yang, C. H., and Shyua, J. Z. (2013). A comparison of innovation policy in the smart grid industry across the pacific: China and the USA. Energy Policy 57, 119-132. doi: 10.1016/j.enpol.2012.12.028

Mustafa, M. A., Zhang, N., Kalogridis, G., and Fan, Z. (2014). "Roaming electric vehicle charging and billing: an anonymous multi-user protocol," in 2014 IEEE International Conference on Smart Grid Communications (SmartGridComm) (Venice), 939-945.

Rathnayaka, A. D., Potdar, V., and Ou, M. H. (2012). "Prosumer management in socio-technical smart grid," in Proceedings of the CUBE International Information Technology Conference (Pune), 483-489.

Rodríguez, R., Madina, C., and Zabala, E. (2015). "EV integration in smart grids through interoperability solutions," in EVS28 Int Electric Veh Symp Exhibition (Goyang), 1-12.

Sanseverino, E. R., and Sanseverino, R. R. (2018). "Smart urban energy districts and energy policies," in 2018 IEEE Green Technologies Conference (GreenTech) (Austin, TX), 144-148.

Schuh, G., Fluhr, J., Birkmeier, M., and Sund, M. (2013). "Information system architecture for the interaction of electric vehicles with the power grid," in $10^{\text {th }}$ IEEE International Conference on Networking, Sensing, and Control (ICNSC) (Paris), 821-825.

Shuai, W., Maillé, P., and Pelov, A. (2016). Charging electric vehicles in the smart city: a survey of economy-driven approaches. IEEE Trans. Intell. Transp. Syst. 17, 2089-2106. doi: 10.1109/TITS.2016.2519499

Spickermann, A., Grienitz, V., and Heiko, A. (2014). Heading towards a multimodal city of the future? multi-stakeholder scenarios for urban mobility. Technol. Forecast. Soc. Change 89, 201-221. doi: 10.1016/j.techfore.2013.08.036

Tcholtchev, N., Farid, L., Marienfeld, F., Schieferdecker, I., Dittwald, B., and Lapi, E.
(2012). "On the interplay of open data, cloud services and network providers towards electric mobility in smart cities," in 37th Annual IEEE Conference on Local Computer Networks-Workshops (Clearwater, FL), 860-867.

Vaidya, B., and Mouftah, H. T. (2018). "Protecting the privacy of electricity consumers in the smart city," Transportation and Power Grid in Smart Cities: Communication Networks and Services, eds H. T. Mouftah, Melike, M. Erol-Kantarci, and M. H. Rehmani Hoboken, NJ: John Wiley and Sons Ltd), 529-554.

Wang, S., Fan, J., Zhao, D., Yang, S., and Fu, Y. (2016). Predicting consumers' intention to adopt hybrid electric vehicles: using an extended version of the theory of planned behavior model. Transportation 43, 123-143. doi: 10.1007/s11116-014-9567-9

Watson, R. T., Boudreau, M. C., and Chen, A. J. (2010). Information systems and environmentally sustainable development: energy informatics and new directions for the IS community. MIS Q. 23-38. doi: 10.2307/20721413

Weiller, C., and Neely, A. (2014). Using electric vehicles for energy services: Industry perspectives. Energy 77, 194-200. doi: 10.1016/j.energy.2014.06.066

Zame, K. K., Brehm, C. A., Nitica, A. T., Richard, C. L., and Schweitzer, I. I. I., G. D. (2018). Smart grid and energy storage: policy recommendations. Renew. Sustain. Energy Rev. 82, 1646-1654. doi: 10.1016/j.rser.2017.07.011

Zuccalà, M., and Verga, E. S. (2017). Enabling energy smart cities through urban sharing ecosystems. Energy Proc. 111, 826-835. doi: 10.1016/j.egypro.2017.03.245

Conflict of Interest: The author declares that the research was conducted in the absence of any commercial or financial relationships that could be construed as a potential conflict of interest.

Copyright (c) 2021 Anthony Jnr. This is an open-access article distributed under the terms of the Creative Commons Attribution License (CC BY). The use, distribution or reproduction in other forums is permitted, provided the original author(s) and the copyright owner(s) are credited and that the original publication in this journal is cited, in accordance with accepted academic practice. No use, distribution or reproduction is permitted which does not comply with these terms. 